\title{
Movilidad Laboral e Informalidad: \\ La situación argentina en el período 1998-2006
}

\author{
Alumno: Leopoldo Tornarolli ${ }^{1}$
}

Director: Dr. Gonzalo Fernández

Tesis de la Maestría en Economía

Facultad de Ciencias Económicas

Universidad Nacional de La Plata

La Plata, 25 de Abril de 2008

\footnotetext{
${ }^{1}$ Los errores y omisiones en el contenido de este documento permanecen bajo entera responsabilidad del autor. Para sugerencias y/o comentarios, escribir a: tornarolli@yahoo.com.ar
} 


\section{Motivación}

Si bien existen numerosos trabajos al respecto, el análisis de la informalidad laboral se ha incorporado a la literatura económica no hace mucho tiempo atrás. Dicha incorporación se vincula a la aparición de otros conceptos relacionados: economía oculta e informal, precariedad y marginalidad laboral, etc. A pesar de tratarse de un área de estudio relativamente nueva, puede encontrarse un gran número de trabajos que se ocupan de analizar el fenómeno, buscando caracterizarlo, definirlo y explicar sus orígenes y determinantes.

En una buena medida, esta proliferación de investigaciones se fundamenta en las características propias del objeto de estudio: la informalidad es un fenómeno complejo, involucra varias dimensiones más allá de la laboral propiamente dicha y sus manifestaciones no sólo han ido cambiando en el tiempo y sino que también difieren entre países. De este modo, no es de extrañar que exista un largo debate, aún abierto, respecto a la definición y conceptualización del fenómeno. Tampoco sorprende la existencia de teorías y enfoques diversos que buscan explicar los orígenes, las características y los determinantes de la informalidad.

Entre las teorías que tratan de entender y explicar los factores que determinan la informalidad laboral, uno de los factores que divide las aguas entre quienes se encuentran a favor o en contra de una teoría u otro es la posición que se adopte respecto a la naturaleza de la informalidad: ¿es esta un fenómeno voluntario o impuesto? La importancia de sostener uno u otro punto de vista se vuelve más clara al notarse que la interpretación de los resultados observados en el mercado laboral y las posibles intervenciones de política económica que se desprenden de ello resultan marcadamente diferentes según uno se sitúe en uno u otro bando.

En nuestro país las discusiones e investigaciones en la materia aparecieron prácticamente en el mismo momento que nació el interés en la informalidad en América Latina, alrededor de 1960. Pero el principal incentivo y disparador de numerosos trabajos al respecto lo constituyó el rápido crecimiento de la informalidad laboral que comienza a principios de la última década del siglo pasado y que se extiende hasta estos días.

Las motivaciones detrás de este trabajo provienen, básicamente, de los aspectos señalados con anterioridad. La aparición, el crecimiento y la persistencia de la informalidad laboral en Argentina implican que este debe ser un tema sumamente importante en la agenda de estudios relacionados al mercado laboral en nuestro país. A su vez, la existencia de diferentes perspectivas teóricas, en la literatura especializada, sobre el la informalidad laboral 
estimula los estudios empíricos destinados a encontrar evidencia que ayude a comprender mejor el fenómeno y permita refinar aún más la discusión teórica.

Siguiendo entonces los incentivos mencionados, en este trabajo se busca realizar un aporte principalmente empírico al estudio y análisis de la informalidad laboral, con particular atención a lo que sucede en Argentina. El enfoque que se utilizará, basado en el análisis de la informalidad en distintas etapas del ciclo económico y en el estudio de la misma dentro de la dinámica del mercado laboral (movilidad entre ocupaciones, búsqueda y deseo de cambiar de empleo y sector de trabajo) constituye también una contribución al conocimiento del fenómeno en el país, dado que dicho punto de vista ha sido escasamente estudiado hasta el momento.

A continuación, la Sección 2, contiene una breve discusión sobre las definiciones de informalidad laboral que han aparecido y que más comúnmente se presentan en la literatura, explicitando la definición adoptada en este trabajo. En la Sección 3 se profundiza en el debate teórico sobre informalidad, presentando las dos teorías principales que buscan explicar las razones detrás de la informalidad laboral. Luego de describir los datos utilizados en la Sección 4, la Sección 5 presenta información sobre la evolución de la informalidad laboral en Argentina desde 1998 hasta 2006, evaluándose algunos aspectos destacados de la misma. La Sección 6 constituye el centro del trabajo, a partir de mostrar y estudiar la información relativa a la movilidad observada entre diferentes estados laborales en diferentes períodos, incluyendo entre dichos estados la posibilidad de diferentes tipos de trabajo informal. Asimismo, en dicha Sección se realiza un análisis de los factores que determinan que un trabajador ocupado decida buscar un empleo diferente al que posee. Finalmente, en la Sección 7 se realiza un repaso de los resultados encontrados, evaluando el aporte de los mismos a la discusión sobre la informalidad laboral.

\section{Definición de Informalidad}

Como fuera mencionado, existe un debate aún no cerrado sobre la definición del concepto de informalidad, que se extiende más allá de la informalidad laboral, abarcando diferentes aspectos del funcionamiento del sistema económico. En lo que respecta a la informalidad laboral propiamente dicha, prácticamente la totalidad de los trabajos empíricos se inclinan por utilizar una de dos definiciones alternativas de informalidad, que tienen en 
cuenta distintas características de la situación laboral de los individuos y que, en parte, se complementan. ${ }^{2}$

Una de esas definiciones generalmente empleadas es la que se conoce como definición "productiva" de informalidad laboral. En este caso se asocia la informalidad a partir de considerar aspectos relacionados a la unidad productiva y a la tecnología de producción. De este modo, se definen como trabajadores informales a todos aquellos que poseen trabajos de baja productividad, con niveles reducidos de calificación, en sectores marginales de la economía, con escasa utilización de capital y tecnología por trabajador, etc.

Por su parte, la denominada definición “legal” enfatiza la relación de las unidades de producción y el marco regulatorio, considerando como informales a aquellos trabajadores que no tienen acceso a los diversos beneficios de la seguridad social (como ser jubilaciones y pensiones, seguro de salud, derecho a vacaciones, etc.) y/o cuyas actividades no se encuentran registradas, debido a la falta de contrato laboral.

Claramente, el avance de la literatura en términos de definición de informalidad laboral ha estado más vinculado a la identificación de características del fenómeno (que hacen posible la implementación empírica de diferentes definiciones) que a la enunciación teórica de una definición clara del concepto.

Desde el punto de vista empírico, ambas definiciones presentan ciertas dificultades de implementación. En el caso de la definición productiva, algunos elementos presentes en la definición son inobservables (la productividad), mientras que sobre otros (la dotación de capital) no se incluye información en las fuentes de datos existentes. La definición legal tampoco esta exenta de problemas a la hora de volver operable el concepto. Las dimensiones que abarca la seguridad social son muchas y varían entre países, por lo que es casi imposible encontrar una definición aplicable a distintos países y contextos. Adicionalmente, las encuestas de hogares y de empleo, fuentes principales de microdatos para el análisis empírico, muchas veces no contienen información suficiente de aspectos relacionados con la seguridad social y los beneficios sociales a los que acceden los trabajadores.

En este trabajo, debido a que se pretende estudiar la movilidad entre diversas categorías ocupacionales, se ha preferido utilizar definición productiva de informalidad

\footnotetext{
${ }^{2}$ Para una discusión más detallada, véase Fields (1990), Portes and Schauffler (1993), Pradhan and van Soest (1995), Saavedra and Chong (1999), Maloney (1999), Guha-Khasnobis et al. (2006), Henley et al. (2006) y Gasparini y Tornarolli (2006).
} 
laboral. Las categorías o estados ocupacionales que se tendrán en consideración son las siguientes:

a. Personas Inactivas

b. Trabajadores Desocupados

c. Trabajadores Asalariados Formales

d. Trabajadores Cuentapropistas Formales

e. Trabajadores Asalariados Informales

f. Trabajadores Cuentapropistas Informales

g. Trabajadores no Remunerados

h. Empleadores o Patrones

Las definiciones de inactividad y desocupación empleadas corresponden a las definidas oficialmente por el Instituto Nacional de Estadísticas y Censos (INDEC). En la primera categoría se incluyen todos aquellos individuos que no trabajaron ni buscaron trabajo en la semana previa a la realización de la encuesta. Como desocupados se incluyen los incluyen los individuos que no trabajaron pero estuvieron buscando trabajo en la semana previa a la entrevista.

Dentro de la categoría de trabajadores asalariados formales se incluyen a todos los individuos que trabajan en firmas de seis o más trabajadores y a los empleados públicos. Adicionalmente se agregan en esta categoría a todos los trabajadores asalariados (en firmas de cualquier tamaño) que cuentan con $\underline{\text { todos }}$ los beneficios sociales vinculados al trabajo sobre los que indaga la Encuesta Permanente de Hogares (EPH): derecho a indemnización por despido, percepción de aguinaldo, derecho a vacaciones pagas, aportes jubilatorios y cobertura del seguro de trabajo.

Siguiendo la práctica tradicional, se considera a los asalariados que trabajan en pequeñas empresas (cinco o menos trabajadores) dentro del grupo de trabajadores informales. El supuesto implícitamente usado en esta definición (y en la anterior) es que la mayoría de los trabajadores asalariados en dichas firmas operan utilizando poco capital, con tecnologías primitivas y tienen baja productividad. Con un criterio similar al utilizado en el párrafo anterior, se consideran también en esta categoría a todos los trabajadores asalariados (en firmas de cualquier tamaño) que no acceden a ninguno de los beneficios sociales vinculados al trabajo que releva la EPH. 
Si bien en general se relaciona directamente el nivel de informalidad laboral con el nivel de trabajo independiente, en este trabajo se separan los cuentapropistas profesionales de aquellos que no son profesionales, considerando dentro de la informalidad solamente a estos últimos. La razón por la que se toma esta decisión es que los primeros normalmente son trabajadores altamente productivos y están plenamente incorporados en la economía moderna. De hecho, los profesionales independientes poseen ingresos muy elevados en relación al resto de las categorías. A su vez, dicho grupo representa un mayor porcentaje del empleo por cuenta propia en nuestro país que en cualquier otro país de América Latina. ${ }^{3}$

Finalmente, también se incluyen dentro del grupo de trabajadores informales a los trabajadores no remunerados. En general, las encuestas cuentan con esta categoría para incluir principalmente a trabajadores familiares, es decir, trabajadores que participan de actividades dentro de una empresa familiar pero que no reciben un salario formal por su participación. Como se verá, dicho grupo no es de mayor importancia en nuestro país.

La inclusión de los patrones en el sector formal es debatible, dado que, en la práctica, algunos de ellos son cuentapropistas en actividades de baja productividad, en las que utilizan poco capital y algún trabajador poco calificado (un ejemplo de ello es el de un albañil que contrata un peón). Siguiendo a la práctica usual, este grupo ha sido incluido dentro de los trabajadores formales.

\section{Antecedentes Teóricos sobre la Informalidad Laboral}

Como ya fuera mencionada anteriormente existen varias perspectivas diferentes sobre los orígenes de la informalidad laboral. Básicamente se podría identificar dos principales teorías, que si bien pueden verse como antagónicas en la realidad pueden ser complementarias a la hora de entender realidades complejas. Incluso en un país, en un momento dado, cada una de las teorías puede explicar una parte del fenómeno de la informalidad laboral. Estas dos teorías son comúnmente conocidas como la teoría de la exclusión y la teoría del escape.

La teoría de "exclusión" tiene una mayor tradición histórica, ya que podría decirse que surge prácticamente al mismo tiempo que se empieza a hablar de informalidad laboral. Según esta teoría existe un sector informal que absorbe a todos aquellos trabajadores en la fuerza laboral que no pueden conseguir empleos en el sector formal de la economía. ${ }^{4}$ No solo estos trabajadores se encuentran en desventaja por la imposibilidad de acceder a los trabajos

\footnotetext{
${ }^{3}$ Ver Gasparini y Tornarolli (2006).

${ }^{4}$ Ver Fields (1990).
} 
más productivos y con mejores remuneraciones que ofrece el sector moderno de la economía, sino que también son excluidos de aquellos beneficios que otorga el Estado. Según esta visión el sector moderno actúa como un nexo entre el empleo formal y el desempleo, no sólo porque recibe a la parte de la fuerza laboral que no incorpora o expulsa el sector formal, sino también porque es la puerta de entrada al mercado laboral de los jóvenes no calificados que se incorporan a la población económicamente activa. De este modo, el sector informal es principalmente percibido como un sector de subsistencia al que recurren todos aquellos que no pueden emplearse en el sector formal de la economía debido a que la cantidad de empleos disponibles en el mismo no es suficiente para cubrir la cantidad de trabajadores que ofrecen su trabajo en él, dado que el salario fijado en el mismo es artificialmente alto, debido a fallas de mercado, intervenciones estatales (por ejemplo fijando un salario mínimo) u otro tipo de intervenciones que impiden que el salario baje al nivel que produciría el equilibrio de mercado.

Los factores que impiden que se equilibre el mercado laboral en el sector formal no operan en el sector informal, entonces hacia este se dirigen los trabajadores excedentes que no consiguen empleo en el primer sector. De este modo los salarios en el sector informal se deprimen lo suficiente como para absorber al remanente del mercado formal. Como resultado no sólo los trabajadores informales quedan fuera del circuito moderno de la economía, sino que también perciben salarios más bajos y no tienen accesos a los beneficios sociales vinculados al empleo formal.

En contraste a esta teoría, la visión integrada de la informalidad laboral enfatiza el carácter voluntario del trabajo informal. Según este punto de vista, los individuos pueden elegir trabajos informales voluntariamente: dadas sus preferencias, habilidades, formas alternativas de protección social y su valuación personal de costos y beneficios del trabajo formal e informal, ciertos trabajadores optan por el “escape”. En otras palabras, ser informal es óptimo para algunos trabajadores. Detrás de esta noción está la idea de que los trabajos formales e informales no difieren únicamente en el acceso a la seguridad social y que los beneficios formales son sólo un elemento más dentro de los cálculos de los trabajadores. ${ }^{5}$

En diferentes situaciones estos cálculos de los beneficios pueden resultar en que para ciertos trabajadores sea preferible trabajar en el sector informal. El cuentapropismo, normalmente asociado con la informalidad en esta visión, puede proveer al trabajador mayor flexibilidad e independencia. A su vez los costos de oportunidad del mismo pueden ser bajos

\footnotetext{
${ }^{5}$ Para más detalles sobre ambas visiones ver Perry et. al. 2007.
} 
para ciertos trabajadores ya que dadas sus calificaciones y otras características personales, su productividad y remuneraciones en el sector formal de la economía serían muy bajas. En este sentido la informalidad sería voluntaria y no impuesta.

Perry et. al. (2007) encuentran que los factores que excluyen a ciertos trabajadores y los condicionan a ser parte del sector informal son importantes en toda América Latina y tienen un impacto negativo sobre la productividad y el bienestar.

Sin embargo, los autores encuentran que la opción de escape complementa a la teoría tradicional de la exclusión. Los trabajadores independientes, por ejemplo, dicen estar en promedio tan bien como los trabajadores en empleos formales para los cuales ellos están calificados. Es decir, la mayoría de ellos no está buscando empleo en el sector formal. La mayor parte de esos trabajadores informales seleccionaron sus ocupaciones de acuerdo a sus necesidades individuales (especialmente su deseo de flexibilidad y autonomía) y sus aptitudes (su ventaja comparativa dada su capacidad empresarial).

A su vez, se observa una situación distinta para la mayoría de los trabajadores informales asalariados en los países estudiados. Así, la mayoría de los asalariados informales están buscando empleos más "deseables", ya sea como asalariados en el sector formal o como trabajadores independientes. Para muchos de estos trabajadores, la informalidad refleja en gran medida la decisión de las empresas para las que trabajan, especialmente las microempresas, de operar fuera del ámbito de las reglamentaciones gubernamentales. En promedio, estos trabajadores no deciden por sí mismos permanecer fuera de los contratos formales ni de las instituciones de la seguridad social, y preferirían tener un trabajo equivalente en el sector formal. En estos casos, la exclusión, y no el escape, parece ser la razón por la que se encuentran actualmente en el sector informal.

En este trabajo se buscará en responder preguntas que se derivan del debate entre las visiones de informalidad, entre ellas ¿Cuan importante es cada una de las teorías en nuestro país a la hora de explicar la informalidad laboral? ¿Adquirió características diferentes el fenómeno de la informalidad luego de la fuerte crisis económica sufrida en 2001-02?

\section{Datos Utilizados}

Todas las estadísticas presentadas en esta sección y en el resto del trabajo se obtienen a partir de los microdatos de la EPH. La EPH es llevada a cabo por el INDEC. Actualmente cubre 31 aglomerados urbanos, todos ellos con más de 100.000 habitantes, que representan al $71 \%$ de la población urbana del país. Dado que la participación de las áreas urbanas en el total 
de la población nacional es de aproximadamente un 87\%, la muestra de la EPH representa cerca del $62 \%$ de la población argentina. La EPH reúne información sobre características sociodemográficas, condición laboral, horas de trabajo, salarios, ingresos, tipo de empleo, educación, etc. Los microdatos de la EPH están disponibles para el Gran Buenos Aires desde 1974. El resto de las áreas urbanas han sido incorporadas gradualmente en el transcurso de las últimas tres décadas.

Tradicionalmente, la EPH se realizaba dos veces al año (metodología puntual), en los meses de mayo y octubre. En el 2003, el INDEC implementó un importante cambio metodológico, que incluyó cambios en los cuestionarios y en la frecuencia de las visitas a los hogares encuestados (metodología continua). A su vez, el número de observaciones (individuos) ha cambiado de 90.000 aproximadamente en los 90s, a cerca de 60.000 a principios de 2000 y más de 100.000 en la nueva EPH Continua (EPH-C).

En este trabajo tomamos las EPH puntuales de octubre para el período 1998-2002 y las EPH-C (cuarto trimestre) para 2003-2006. Lamentablemente no se encuentra aún disponible al público la información del año 2007. A partir de estas encuestas, es posible construir paneles que permiten seguir a un mismo individuo por un año y medio. Mediante los mismos, se realizará un análisis de los movimientos de los trabajadores entre distintos estados ocupacionales.

Como se mencionó anteriormente, hasta el 2003 la EPH se realizaba de manera puntual en los meses de mayo y octubre de cada año. De un año a otro sólo se renovaba el $25 \%$ de los hogares encuestados en la muestra por lo que el $75 \%$ de la muestra podía ser observado durante seis meses, el $50 \%$ por un año y el $25 \%$ por un año y medio. Luego del cambio metodológico de la EPH, la encuesta es realizada trimestralmente y el esquema de rotación se ha modificado. Desde 2003, los hogares ingresan en la muestra por dos trimestres consecutivos, se retiran por dos trimestres consecutivos y luego, vuelven a ser entrevistados en dos trimestres consecutivos. Es decir, entre un trimestre y otro existe un $50 \%$ de muestra común, al igual que entre un trimestre y el mismo trimestre del año siguiente. Sin embargo, entre un trimestre y otro no consecutivo (separado por un trimestre intermedio) no hay muestra en común. A su vez, entre un semestre y el inmediatamente siguiente existe un solapamiento de $37 \%$ de la muestra. Pese a los cambios en la rotación de la muestra, este esquema permite observar a un hogar a lo largo de un año y medio, tal como sucedía en el caso de la EPH puntual. 
Teniendo en cuenta estas características de la EPH y EPH-C se construyeron siete paneles anuales, desde 1998 a $2006^{6}$, a partir de los cuales se puede estudiar la movilidad entre diferentes categorías laborales. Se incluyen todos los aglomerados para los cuales se cuenta información en este período.

\section{La Evolución del Mercado Laboral y la Informalidad}

A continuación, se realiza la estimación y el análisis de varios indicadores de la estructura y evolución del mercado laboral argentino. Se presta especial atención a lo que ocurrió con la informalidad laboral en el período 1998-2006. Adicionalmente, se estudia lo ocurrido con los ingresos laborales en las diferentes categorías.

\section{La Informalidad Laboral}

En la Tabla 1 se presenta la estructura del mercado laboral, en términos del porcentaje de trabajadores en cada una de las categorías ocupacionales mencionadas previamente, para el período 1998-2006. Si bien la estructura laboral parece ser similar en todos los años, se pueden encontrar algunas diferencias que son importantes. La participación de los asalariados formales, a partir de 1998, experimentó una tendencia decreciente que se profundizó durante la crisis de 2001-2002. Con la recuperación económica posterior se produce una reversión de dicha tendencia, siendo el año 2006 el que muestra la mayor participación del empleo asalariado formal en el período bajo análisis. Por su parte, la participación de los asalariados informales creció en casi todos los años entre 1998 y 2004, para caer en los dos últimos años, aunque la magnitud de dicha caída es menor que la del aumento del empleo asalariado formal. En 2006 la participación de asalariados informales era un 20\% superior a la que el mismo grupo tenía en 1998.

Por su parte, el porcentaje de desocupados mostró un comportamiento opuesto al empleo asalariado formal, se incrementó hasta 2002 y luego se produjo una caída significativa una vez superada la crisis económica. La participación de los cuentapropistas (ya sean formales o informales) no se ha visto modificada mayormente en el período bajo análisis, siendo lo más destacado una pequeña tendencia a la caída del empleo cuentapropista informal a partir de 2001. Lo mismo ocurrió con el share de trabajadores sin remuneración y los

\footnotetext{
${ }^{6}$ Los cambios mencionados en la estructura de la EPH impiden construir un panel para 2002-2003.
} 
patrones, aunque estos últimos dos grupos poseen una participación muy baja sobre el total del empleo, al igual que los cuentapropistas formales.

Tabla 1

Trabajadores por Categoría Laboral

Población de entre 15 y 64 años

\begin{tabular}{|c|c|c|c|c|c|c|c|c|c|}
\hline & \multirow{2}{*}{ Inactivos } & \multirow{2}{*}{ Desocupados } & \multicolumn{2}{|c|}{ Formales } & \multicolumn{2}{|c|}{ Informales } & \multirow{2}{*}{ Sin Salario } & \multirow{2}{*}{ Patrones } & \multirow{2}{*}{ Total } \\
\hline & & & Asalariados & Cuentapropistas & Asalariados & Cuentapropistas & & & \\
\hline 1998 & 35.9 & 8.1 & 25.6 & 1.6 & 15.4 & 10.2 & 0.7 & 2.5 & 100.0 \\
\hline 1999 & 35.6 & 9.1 & 25.2 & 1.5 & 15.5 & 10.1 & 0.7 & 2.4 & 100.0 \\
\hline 2000 & 35.3 & 9.7 & 24.4 & 1.5 & 15.8 & 10.3 & 0.7 & 2.4 & 100.0 \\
\hline 2001 & 36.2 & 11.9 & 22.7 & 1.6 & 14.6 & 10.4 & 0.5 & 2.2 & 100.0 \\
\hline 2002 & 35.0 & 11.8 & 21.7 & 1.7 & 17.1 & 10.3 & 0.5 & 2.1 & 100.0 \\
\hline 2003 & 31.3 & 10.3 & 23.5 & 1.6 & 20.2 & 10.3 & 0.8 & 2.2 & 100.0 \\
\hline 2004 & 31.0 & 8.5 & 24.8 & 1.9 & 20.6 & 9.9 & 0.8 & 2.5 & 100.0 \\
\hline 2005 & 31.6 & 7.1 & 26.9 & 2.1 & 19.5 & 9.8 & 0.7 & 2.4 & 100.0 \\
\hline 2006 & 32.0 & 6.1 & 28.6 & 1.8 & 18.7 & 9.6 & 0.6 & 2.5 & 100.0 \\
\hline
\end{tabular}

En términos totales, la informalidad laboral medida de acuerdo a las categorías anteriormente mencionadas creció hasta el 2003 y cayó desde entonces y hasta 2006. Lógicamente, la evolución del porcentaje de trabajadores formales ha sido exactamente opuesta, alcanzando su mínimo en el 2003 y creciendo a partir de entonces, como se observa en la Figura 1. La principal fuerza que explica estos resultados es la evolución del empleo asalariado formal e informal.

Figura 1

Participación de Trabajadores Formales e Informales

Población de entre 15 y 64 años

Trabajadores Informales

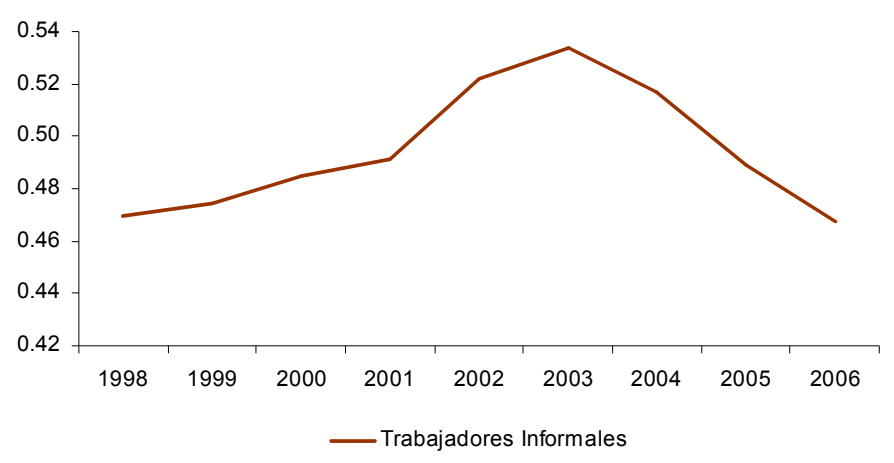

Fuente: elaboración propia en base a EPH.

En la Tabla 2 que se muestra a continuación, se exhibe la evolución de la participación en el empleo informal de cada una de las categorías entre las que se reparten los trabajadores informales (asalariados, cuentapropistas y sin salario). Si bien los cambios son suaves, la 
comparación entre extremos de la serie indica un incremento importante en la proporción de los asalariados informales sobre el total de los informales, a la vez que se produce una reducción en la participación de los cuentapropistas informales.

Tabla 2

Trabajadores Informales, por Categoría Laboral Población de entre 15 y 64 años

\begin{tabular}{ccccc}
\hline & Asalariados & Cuentapropistas & Sin Salario & Total \\
\hline $\mathbf{1 9 9 8}$ & 58.4 & 38.8 & 2.8 & 100.0 \\
$\mathbf{1 9 9 9}$ & 58.9 & 38.4 & 2.7 & 100.0 \\
$\mathbf{2 0 0 0}$ & 59.0 & 38.6 & 2.4 & 100.0 \\
$\mathbf{2 0 0 1}$ & 57.3 & 40.9 & 1.8 & 100.0 \\
$\mathbf{2 0 0 2}$ & 61.4 & 37.0 & 1.7 & 100.0 \\
$\mathbf{2 0 0 3}$ & 64.5 & 33.0 & 2.5 & 100.0 \\
$\mathbf{2 0 0 4}$ & 66.0 & 31.6 & 2.4 & 100.0 \\
$\mathbf{2 0 0 5}$ & 65.0 & 32.7 & 2.3 & 100.0 \\
$\mathbf{2 0 0 6}$ & 64.6 & 33.2 & 2.2 & 100.0 \\
\hline \multicolumn{5}{r}{}
\end{tabular}

En resumen, la informalidad laboral se incrementó sustancialmente entre 2002 y 2004. El aumento del desempleo entre 1998 y 2002 tuvo como contrapartida una caída importante en el empleo asalariado formal, mientras que la recuperación de la crisis posterior permitió reducir significativamente el desempleo mediante un aumento del empleo asalariado formal e informal. Dado que el empleo por cuenta-propia informal se mantuvo relativamente estable durante todo el período bajo análisis, los resultados muestran que en 2006 la composición del empleo informal es claramente diferente a la que tenía en 1998: la participación de los asalariados entre los informales es mayor al final del período, siendo la contrapartida una menor participación del empleo cuentapropista informal.

\section{Movilidad e Informalidad}

En esta sección del trabajo se lleva a cabo un análisis de la evolución observada en la informalidad laboral, que fuera mencionada en la sección anterior, a partir de la evaluación de la dinámica de los trabajadores en el mercado laboral. Para ello se construyen matrices de transición, las cuales resumen la información relativa al flujo de trabajadores entre distintas categorías laborales. El objetivo de la sección es proveer evidencia empírica que permita entender lo ocurrido con la informalidad laboral, no sólo el aumento y posterior disminución que esta tuvo, sino también los cambios en su composición interna entre asalariados y 
cuentapropistas. Adicionalmente se analiza en que medida los resultados encajan con una $\mathrm{u}$ otra de las teorías sobre las razones de la informalidad laboral.

\subsection{Estadísticas Descriptivas}

En esta sub-sección se presenta información descriptiva, a partir de la cual se obtiene una primera aproximación a la dinámica en el mercado laboral. Esta información es presentada en forma de matrices de transición, construidas a partir de agrupar a la población en diferentes categorías ocupacionales.

En adelante, se consideran las seis primeras categorías laborales definidas previamente, es decir, inactivos, desocupados, asalariados formales, cuentapropistas formales, asalariados informales y cuentapropistas informales. Los trabajadores no remunerados y los empleadores no fueron incluidos en las matrices para facilitar la lectura y comprensión de las mismas, además de su poca importancia relativa en la explicación de las dinámicas laborales. Por su parte, los cuentapropistas formales fueron incluidos para tratar de comprobar si su comportamiento es significativamente diferente al de los cuentapropistas informales, tal como se supone que ocurre en nuestro país, y se justifica el no considerarlos como trabajadores informales. Más allá de estos comentarios, los cálculos también fueron realizados incluyendo todas las categorías y la inclusión o exclusión de las categorías mencionadas no modifican mayormente el análisis.

La información de las transiciones se presentará para los períodos 1998-99, 2001-02 y 2005-06. Se considera que dichos períodos pueden resultar interesantes por tratarse de una observación anterior a la crisis económica, una observación durante la crisis y una observación de la recuperación posterior a la crisis. Una vez más, los cálculos fueron realizados para todos los períodos de un año de duración a partir de octubre de 1998 y hasta 2006, pero no son presentados por cuestiones de espacio y facilidad de lectura.

En las Tablas 3 a 5 no se muestran directamente las probabilidades de transición entre categorías laborales, sino que presentan los valores promedio de edad y años de educación para cada grupo de individuos que realiza alguna de las transiciones posibles (en total son 35 posibles transiciones, ya que se consideran 6 categorías ocupacionales iniciales y 6 finales. Nótese que la transición desde el cuentapropismo formal hacia el cuentapropismo informal no es posible por definición, ya que la primera categoría incluye trabajadores con estudios superiores completos y la segunda con estudios menores a superior completo). 
La Tabla 3 exhibe que la edad media de los individuos que permanecen en cada una de las categorías de origen al final de cada período es, en casi todos los casos, mayor a la edad media de los individuos que pertenecían a la categoría respectiva al inicio del período (dato que se observa en la columna sombreada a la derecha de la matriz), mostrando una relación positiva entre edad y estabilidad laboral. Otro resultado es que los trabajadores cuentapropistas formales e informales tienen una mayor edad promedio que los asalariados formales e informales. Por su parte, dentro de ambas categorías, los trabajadores formales tienen una edad promedio mayor que los informales.

Los resultados más interesantes tienen que ver con el flujo de trabajadores desde y hacia la informalidad. En esos movimientos se descubren varias regularidades:

a) los trabajadores que se desplazan hacia la categoría asalariado informal tienen, en promedio, menor edad que el promedio de los trabajadores de la categoría de origen;

b) los trabajadores que se desplazan desde el trabajo asalariado informal hacia el cuentapropismo (formal e informal) son, en promedio, mayores que el promedio de los trabajadores asalariados informales en el período inicial; $y$

c) los trabajadores que se desplazan desde el trabajo por cuenta propia informal hacia las restantes categorías son, en promedio, más jóvenes que la media de los cuentapropistas informales en el período inicial. 
Tabla 3

Matrices de Transición: 1998-1999, 2001-2002, 2005-2006

Edad Promedio de los Individuos en cada Grupo

Población de entre 15 y 64 años

\begin{tabular}{|c|c|c|c|c|c|c|c|}
\hline \multirow[b]{2}{*}{ Edad } & \multirow[b]{2}{*}{ Inactivos } & \multirow[b]{2}{*}{ Desocupados } & \multicolumn{2}{|c|}{ Formales } & \multicolumn{2}{|c|}{ Informales } & \multirow[b]{2}{*}{ Media } \\
\hline & & & Asalariados & Cuentapropistas & Asalariados & Cuentapropistas & \\
\hline Inactivos & 33.9 & 27.4 & 30.4 & 39.3 & 27.4 & 37.9 & 33.2 \\
\hline Desocupados & 34.1 & 32.3 & 30.6 & 48.6 & 31.0 & 40.8 & 33.3 \\
\hline Asalariados Formales & 41.1 & 32.4 & 38.5 & 43.8 & 36.0 & 40.1 & 38.2 \\
\hline Cuentapropistas Formales & 32.3 & 42.1 & 39.3 & 43.7 & 35.3 & & 42.4 \\
\hline Asalariados Informales & 33.3 & 34.9 & 32.3 & 38.5 & 33.3 & 38.6 & 34.0 \\
\hline Cuentapropistas Informales & 41.8 & 40.4 & 38.1 & 39.5 & 37.4 & 43.1 & 41.8 \\
\hline \multicolumn{8}{|l|}{ 2001-2002 } \\
\hline & & & \multicolumn{2}{|c|}{ Formales } & \multicolumn{2}{|c|}{ Informales } & \\
\hline Edad & Inactivos & Desocupados & Asalariados & Cuentapropistas & Asalariados & Cuentapropistas & Media \\
\hline Inactivos & 32.8 & 29.9 & 29.2 & 35.3 & 30.7 & 37.7 & 32.5 \\
\hline Desocupados & 33.5 & 34.9 & 32.5 & 34.9 & 32.1 & 40.2 & 34.5 \\
\hline Asalariados Formales & 40.4 & 35.1 & 40.3 & 38.9 & 35.0 & 37.0 & 39.6 \\
\hline Cuentapropistas Formales & 40.3 & 43.5 & 46.1 & 45.5 & 32.2 & & 45.0 \\
\hline Asalariados Informales & 35.5 & 31.2 & 35.4 & 39.7 & 35.2 & 36.9 & 35.0 \\
\hline Cuentapropistas Informales & 40.6 & 39.4 & 38.6 & 39.1 & 37.6 & 44.3 & 41.7 \\
\hline \multicolumn{8}{|l|}{$\underline{2005-2006}$} \\
\hline & & & \multicolumn{2}{|c|}{ Formales } & \multicolumn{2}{|c|}{ Informales } & \\
\hline Edad & Inactivos & Desocupados & Asalariados & Cuentapropistas & Asalariados & Cuentapropistas & Media \\
\hline Inactivos & 33.0 & 30.5 & 27.3 & 44.9 & 29.9 & 37.9 & 32.5 \\
\hline Desocupados & 34.2 & 31.9 & 27.9 & 38.9 & 30.6 & 39.2 & 32.3 \\
\hline Asalariados Formales & 38.5 & 32.7 & 39.6 & 40.5 & 33.5 & 37.8 & 39.0 \\
\hline Cuentapropistas Formales & 44.6 & 48.5 & 39.3 & 44.2 & 43.8 & & 43.8 \\
\hline Asalariados Informales & 35.2 & 28.9 & 33.0 & 35.7 & 35.3 & 38.7 & 34.9 \\
\hline Cuentapropistas Informales & 41.9 & 38.9 & 40.1 & 38.6 & 38.3 & 45.1 & 42.8 \\
\hline
\end{tabular}

Fuente: Elaboración propia en base a la EPH.

En la Tabla 4 se muestran los años de educación promedio para cada uno de los grupos representados en las matrices de transición. En promedio, los trabajadores asalariados formales tienen más años de educación que los informales asalariados y estos últimos superan, nuevamente en promedio, a los cuentapropistas informales. Entre los resultados generales se destaca aquel que muestra que entre los trabajadores formales que permanecen en su categoría laboral el promedio de años de educación es mayor o igual a la media de la categoría correspondiente al inicio del período. Por el contrario, el resultado es el inverso en el caso de trabajadores informales, donde el promedio de años de educación de los que permanecen en cada categoría es menor o igual a la media del grupo al inicio del período, mostrando una mayor movilidad para los más educados.

Analizando las relaciones entre el nivel educativo y las transiciones desde y hacia categorías informales surgen varias conductas de interés:

a) los trabajadores que se desplazan desde la categoría asalariado (cuentapropista) informal hacia el sector asalariado formal tienen más educación promedio que el total de los informales asalariados (cuentapropistas) al inicio del período; por el contrario, los que se 
desplazan desde la misma categoría hacia la categoría cuentapropista (asalariado) informal tienen menos educación que dicho promedio; y

b) los trabajadores que se desplazan hacia las categorías informales (asalariados o cuentapropistas) desde la categoría de trabajo asalariado formal tienen menos años de educación promedio que el total de los trabajadores de su categoría de origen.

Tabla 4

Matrices de Transición: 1998-1999, 2001-2002, 2005-2006 Años de Educación Promedio de los Individuos en cada Grupo Población de entre 15 y 64 años

\begin{tabular}{|c|c|c|c|c|c|c|c|}
\hline \multirow[b]{2}{*}{ Años de Educación } & \multirow[b]{2}{*}{ Inactivos } & \multirow[b]{2}{*}{ Desocupados } & \multicolumn{2}{|c|}{ Formales } & \multicolumn{2}{|c|}{ Informales } & \multirow[b]{2}{*}{ Media } \\
\hline & & & Asalariados & Cuentapropistas & Asalariados & Cuentapropistas & \\
\hline Inactivos & 9.2 & 10.0 & 10.6 & 14.2 & 9.7 & 9.4 & 9.4 \\
\hline Desocupados & 9.5 & 9.7 & 10.5 & 15.9 & 8.9 & 7.8 & 9.4 \\
\hline Asalariados Formales & 10.4 & 10.6 & 11.5 & 16.3 & 11.0 & 9.0 & 11.4 \\
\hline Cuentapropistas Formales & 15.6 & 16.4 & 16.8 & 16.8 & 16.3 & & 16.7 \\
\hline Asalariados Informales & 8.7 & 8.3 & 10.9 & 16.5 & 8.9 & 8.5 & 9.1 \\
\hline Cuentapropistas Informales & 8.1 & 8.8 & 9.2 & 13.0 & 8.4 & 8.7 & 8.7 \\
\hline
\end{tabular}

\begin{tabular}{|c|c|c|c|c|c|c|c|}
\hline \multirow[b]{2}{*}{ Años de Educación } & \multirow[b]{2}{*}{ Inactivos } & \multirow[b]{2}{*}{ Desocupados } & \multicolumn{2}{|c|}{ Formales } & \multicolumn{2}{|c|}{ Informales } & \multirow[b]{2}{*}{ Media } \\
\hline & & & Asalariados & Cuentapropistas & Asalariados & Cuentapropistas & \\
\hline Inactivos & 9.5 & 10.5 & 11.9 & 16.0 & 9.2 & 9.6 & 9.6 \\
\hline Desocupados & 9.8 & 9.7 & 12.3 & 15.4 & 8.7 & 8.7 & 9.5 \\
\hline Asalariados Formales & 11.7 & 11.1 & 12.1 & 15.7 & 10.6 & 10.1 & 11.9 \\
\hline Cuentapropistas Formales & 16.5 & 15.7 & 16.0 & 16.8 & 16.4 & & 16.6 \\
\hline Asalariados Informales & 9.6 & 9.1 & 10.9 & 16.1 & 9.0 & 8.3 & 9.3 \\
\hline Cuentapropistas Informales & 8.6 & 8.5 & 9.6 & 14.1 & 8.7 & 8.7 & 8.8 \\
\hline
\end{tabular}

\begin{tabular}{|c|c|c|c|c|c|c|c|}
\hline \multirow[b]{2}{*}{ Años de Educación } & \multirow[b]{2}{*}{ Inactivos } & \multirow[b]{2}{*}{ Desocupados } & \multicolumn{2}{|c|}{ Formales } & \multicolumn{2}{|c|}{ Informales } & \multirow[b]{2}{*}{ Media } \\
\hline & & & Asalariados & Cuentapropistas & Asalariados & Cuentapropistas & \\
\hline Inactivos & 9.6 & 10.3 & 11.9 & 16.1 & 9.5 & 9.6 & 9.7 \\
\hline Desocupados & 9.8 & 10.3 & 11.3 & 15.6 & 9.9 & 9.9 & 10.2 \\
\hline Asalariados Formales & 12.5 & 10.9 & 12.4 & 17.1 & 11.2 & 11.0 & 12.3 \\
\hline Cuentapropistas Formales & 16.5 & 15.7 & 16.5 & 16.4 & 16.3 & & 16.4 \\
\hline Asalariados Informales & 9.7 & 9.2 & 10.8 & 15.4 & 9.1 & 8.5 & 9.5 \\
\hline Cuentapropistas Informales & 8.5 & 9.6 & 10.8 & 13.0 & 8.7 & 9.1 & 9.2 \\
\hline
\end{tabular}

Fuente: Elaboración propia en base a la EPH.

En resumen, los resultados revelan que los asalariados informales son, en promedio, menores que los formales asalariados, los que a su vez son menores que los cuentapropistas informales. Esto provee alguna evidencia favorable a la visión de informalidad voluntaria, que explica que los jóvenes entran como asalariados informales al mercado y sólo luego de acumular experiencia, contactos y capital se establecen como cuentapropistas (o logran ingresar al empleo asalariado formal). A esta idea contribuyen también las evidencias respecto a que el movimiento desde el empleo informal asalariado hacia el empleo informal por cuenta propia esta compuesto por individuos mayores, en promedio, a los de su categoría de origen (los que se mueven parecen tener mayor experiencia) y el movimiento contrario (de cuenta 
propia informal a asalariado informal) se compone de trabajadores en promedio menores a los de su categoría de origen (posiblemente los que "fallan" en establecerse como cuenta propia son menores al promedio de los cuentapropistas).

La educación parece ser un factor que explica los movimientos desde la informalidad a la formalidad: los trabajadores que se mueven desde las categorías informales (asalariados o cuentapropistas) hacia el empleo asalariado formal tienen, en promedio, más años de educación que los trabajadores en sus respectivas categorías de origen. Si a ello se agrega el hecho de que la media de años de educación entre las tres categorías mencionadas es mayor para los asalariados formales, una posible explicación de estos fenómenos es que el nivel educativo se usa como un requisito para asignar los (relativamente) escasos trabajos formales que la economía genera. En particular, es importante la diferencia en años de educación entre los asalariados informales que consiguen moverse hacia el empleo asalariado formal y aquellos del mismo grupo que permanecen en la categoría de origen.

\subsection{Movilidad e Informalidad}

En esta sub-sección se realiza el análisis de la movilidad entre diferentes categorías ocupacionales $^{7}$ consideradas a partir del uso de matrices de transición.

Los diferentes paneles de la Tabla 5, presentada a continuación, contienen las matrices de transición entre las diferentes categorías ocupacionales para los períodos considerados: 1998-99, 2001-02 y 2005-06. Las celdas de dichas matrices contienen la probabilidad condicional $\left(\mathbf{P}_{i j}\right)$ de que un trabajador se encuentre en la categoría ocupacional $\boldsymbol{j}$ al final de un período de tiempo dado $(\boldsymbol{t}+\mathbf{1})$, dado que al inicio de dicha período $(\boldsymbol{t})$ se encontraba en la categoría ocupacional $\boldsymbol{i}$. En otras palabras, siendo $\mathbf{a}_{i j}$ el valor presentado en la celda correspondiente a la fila $\boldsymbol{i}$ y la columna $\boldsymbol{j}$, éste mide el porcentaje de individuos que se encuentran en la categoría $\boldsymbol{j}$ en el período $\boldsymbol{t}+\boldsymbol{1}$ condicional a haber estado en la categoría $\boldsymbol{i}$ en el período $t$.

La suma de los porcentajes de cada fila, en cada matriz de transición, debe totalizar $100 \%$. Para guiar al lector en la interpretación de los resultados, se presentan recuadradas las transiciones entre las categorías de individuos que no se encuentran empleados (inactivos y desocupados) y las transiciones entre las categorías de individuos empleados (asalariados y cuentapropistas, formales e informales). Adicionalmente, se presentan sombreadas y en

\footnotetext{
${ }^{7}$ Nótese que las matrices que se presentan en este trabajo miden transiciones entre categorías ocupacionales, no entre empleos. Podrían darse situaciones en que un individuo cambia de empleo, pero permanece en el mismo sector ocupacional, que no son captados en las matrices de transición.
} 
negrita las celdas correspondientes a la probabilidad de permanecer en la misma categoría ocupacional al final del período.

La Tabla 5 muestra que la movilidad entre categorías laborales no es muy alta en Argentina. En especial, los movimientos parecen ser mayores desde la informalidad hacia la formalidad, que el movimiento contrario. A pesar de ello, varias relaciones de interés surgen al analizar estas matrices de transición con mayor detalle.

Una de ellas es que la categoría que presenta un mayor nivel de permanencia es la de asalariados formales ${ }^{8}$. En general, el ordenamiento en términos de permanencia, por detrás de los asalariados formales, continúa con los trabajadores inactivos, los cuentapropistas formales, los cuentapropistas informales, los asalariados informales y los desocupados. Sin embargo, dicho orden se altera en el período 2001-02, con la ocurrencia de la crisis económica. En dicho período, y con respecto al período 1998-99, se produce una importante caída en la permanencia en la inactividad.

La menor permanencia en la inactividad tiene como contrapartida, lógicamente, una significativa incorporación de individuos al mercado laboral. Como resultado, la matriz de transición 2001-02 muestra una mayor incidencia de la desocupación en aquellos recién incorporados al mercado laboral, como así también una mayor participación de los mismos en el empleo asalariado informal. También se observa en dicho período que la permanencia en el desempleo se vuelve mayor, disminuyendo el porcentaje de individuos que pueden ingresar a un trabajo asalariado formal y aumentando la probabilidad de ingresar en ambas categorías informales desde la desocupación.

Otra "anomalía” ocurrida en el período 2001-02 tiene que ver con la permanencia en el cuentapropismo informal, la cual disminuye significativamente. ¿Hacia donde se movieron dichos cuentapropistas informales? Principalmente hacia otras tres categorías: desocupación, empleo asalariado informal e inactividad. Finalmente, otro efecto de interés de la crisis fue la reducción de la probabilidad de movimiento desde el empleo asalariado informal al formal.

Todas estas "anomalías" que surgen al comparar los flujos de trabajadores entre categorías en el período 2001-02, con los del período 1998-99, desaparecen si observamos lo sucedido en el período 2005-06. En este período aumenta aún más la permanencia en el trabajado asalariado formal, disminuye fuertemente la permanencia en el desempleo (incrementándose significativamente el flujo desde el desempleo al empleo formal), y

\footnotetext{
${ }^{8}$ Maloney (1999) encuentra resultados similares para México en los 90s.
} 
aumenta a niveles parecidos a los de 1998-99 la permanencia en el cuentapropismo informal (reduciéndose el flujo desde esa categoría al desempleo). Otro aumento dentro del movimiento "virtuoso" que ocurre en este período es el de trabajadores informales asalariados hacia empleos formales asalariados (la contraparte de este movimiento es la caída en el flujo desde el empleo informal asalariado hacia la desocupación, que ocurría en 2001-02).

Respecto a la permanencia en los sectores informales aumenta en ambos casos entre extremos del período, sólo que en contextos diferentes: como fuera comentado con anterioridad el sector asalariado informal ahora es más grande (en un 20\%) que lo que era en 1998, mientras que el sector cuentapropista informal vio reducido su tamaño aproximadamente en un 5\% entre 1998 y 2005.

Tabla 5

Matrices de Transición: 1998-99, 2001-02, 2005-06 Población de entre 15 y 64 años

\begin{tabular}{|c|c|c|c|c|c|c|}
\hline & \multirow[b]{2}{*}{ Inactivos } & \multirow[b]{2}{*}{ Desocupados } & \multicolumn{2}{|c|}{ Formales } & \multicolumn{2}{|c|}{ Informales } \\
\hline & & & Asalariados & Cuentapropistas & Asalariados & Cuentapropistas \\
\hline Inactivos & 80.9 & 6.5 & 2.3 & 0.2 & 6.4 & 3.7 \\
\hline Desocupados & 25.2 & 29.6 & 11.9 & 0.6 & 21.4 & 11.3 \\
\hline Asalariados Formales & 2.4 & 3.7 & 83.7 & 0.7 & 7.2 & 2.3 \\
\hline Cuentapropistas Formales & 2.1 & 5.5 & 13.9 & 67.7 & 10.8 & 0.0 \\
\hline Asalariados Informales & 13.6 & 11.7 & 13.9 & 1.0 & 49.3 & 10.5 \\
\hline Cuentapropistas Informales & 11.0 & 8.3 & 2.7 & 1.1 & 17.7 & 59.3 \\
\hline \multicolumn{7}{|l|}{ 2001-2002 } \\
\hline & & & \multicolumn{2}{|c|}{ Formales } & \multicolumn{2}{|c|}{ Informales } \\
\hline & Inactivos & Desocupados & Asalariados & Cuentapropistas & Asalariados & Cuentapropistas \\
\hline Inactivos & 76.1 & 9.2 & 1.5 & 0.2 & 9.5 & 3.5 \\
\hline Desocupados & 21.6 & 33.7 & 5.0 & 1.1 & 25.5 & 13.2 \\
\hline Asalariados Formales & 3.1 & 5.1 & 82.0 & 0.6 & 7.0 & 2.2 \\
\hline Cuentapropistas Formales & 4.0 & 4.6 & 6.5 & 77.7 & 7.2 & 0.0 \\
\hline Asalariados Informales & 13.9 & 12.8 & 11.2 & 0.7 & 50.8 & 10.6 \\
\hline Cuentapropistas Informales & 12.4 & 12.7 & 3.4 & 0.7 & 21.4 & 49.5 \\
\hline \multicolumn{7}{|l|}{$2005-2006$} \\
\hline & & & \multicolumn{2}{|c|}{ Formales } & \multicolumn{2}{|c|}{ Informales } \\
\hline & Inactivos & Desocupados & Asalariados & Cuentapropistas & Asalariados & Cuentapropistas \\
\hline Inactivos & 75.8 & 7.1 & 3.0 & 0.6 & 10.0 & 3.5 \\
\hline Desocupados & 28.4 & 21.1 & 14.2 & 1.1 & 25.4 & 9.8 \\
\hline Asalariados Formales & 2.8 & 1.9 & 86.8 & 0.7 & 6.4 & 1.5 \\
\hline Cuentapropistas Formales & 5.5 & 4.1 & 15.6 & 64.2 & 10.7 & 0.0 \\
\hline Asalariados Informales & 14.5 & 5.1 & 17.3 & 0.5 & 53.2 & 9.5 \\
\hline Cuentapropistas Informales & 11.7 & 3.3 & 4.7 & 1.4 & 17.6 & 61.4 \\
\hline
\end{tabular}

Fuente: Elaboración propia en base a la EPH.

Los resultados presentados hasta ahora no tienen interpretaciones unívocas. Pese a ello, varias historias son sugeridas por los mismos. Una de ellas tiene que ver con el aumento en el tamaño y en la estabilidad en el empleo asalariado (formal e informal), el crecimiento de los movimientos desde otros sectores hacia el empleo asalariado formal y la constancia en el flujo hacia el empleo asalariado informal desde otras categorías de empleo (aún cuando muchos ya se desplazaron al sector con la crisis), hechos todos ocurrido luego de 2001-02. La 
explicación lógica a esto resultados sería que la recuperación permite la apertura de más y mejores puestos de trabajo asalariado formal pero, dado que el fenómeno no se limita al empleo asalariado formal, otra posible explicación complementaria es que la crisis puede haber aumento la "deseabilidad" de los empleos asalariados, ya sea formal o informal, ya que supone ingresos menos fluctuantes que el empleo cuentapropista informal.

Sin embargo, los resultados presentados en la Tabla 5, no permiten hacer una valoración definitiva de la intensidad de los flujos hacia un sector en particular. Como bien señala Maloney (1999), si el movimiento de trabajadores fuera aleatorio, $\mathbf{P}_{i j}$ se incrementaría con $\mathbf{P}_{\boldsymbol{j}}$, el tamaño de la categoría en la que finalizan los trabajadores. Una forma de solucionar este inconveniente consiste en realizar una estandarización de las probabilidades de transición, ajustando las probabilidades condicionales por el tamaño del sector de destino, $\left(\mathbf{P}_{i j}\right.$ ( $\mathbf{P}_{j}$ ). La Tabla 6 presenta los resultados de este ejercicio. La forma de interpretar los resultados es la siguiente: para cada categoría ocupacional $\boldsymbol{i}$, los resultados que se presentan a lo largo de la fila correspondiente muestran si el flujo dentro de cada sector $\boldsymbol{j}$ es más intenso de lo que sería en un caso de movimientos aleatorios.

Del análisis ${ }^{9}$ de la Tabla 6 se obtienen varios resultados interesantes:

Inactivos: las probabilidades estandarizadas muestran que los individuos inactivos tienen una mayor intensidad de movimiento a la desocupación que a cualquier otra categoría ocupacional. Luego de la desocupación, los sectores con más probabilidad de recibir individuos que eran inactivos en el período anterior son los sectores informales asalariados y cuentapropistas, en ese orden. La intensidad de la transición de la inactividad al empleo asalariado formal es relativamente baja. Durante la crisis parece haber aumentado la intensidad de la transición desde la inactividad el empleo informal asalariado.

Desocupados: en este caso la estandarización muestra que los individuos desocupados se mueven con más intensidad hacia el empleo informal, en particular al asalariado, que a cualquier otra categoría. Nuevamente, dicha intensidad se acrecentó durante la crisis, disminuyendo luego de la misma.

Asalariados Formales: estos trabajadores tienen una muy baja intensidad de movimiento hacia la inactividad, siendo dicho flujo explicado, posiblemente, por trabajadores

\footnotetext{
${ }^{9}$ En la mayoría de los análisis prescindiremos de comentar lo que ocurre con los trabajadores cuentapropistas formales, en la medida que corresponden a una categoría de comportamiento muy diferenciado a las restantes y de poca importancia relativa. Sin embargo, los mismos se presentan separados del resto de los cuentapropistas teniendo en cuenta las diferencias antes comentadas.
} 
que se van jubilando. Con respecto a movimientos hacia otras categorías, los movimientos son de similar magnitud, predominando el desplazamiento hacia el empleo asalariado informal antes de la crisis y el desplazamiento a la desocupación durante la misma. Se observa también que existe una caída en la intensidad de los movimientos desde este sector hacia los sectores informales (asalariados y cuentapropistas) entre 1998 y 2006.

Asalariados Informales: estos muestran una mayor intensidad de desplazamiento hacia la desocupación y el cuentapropismo informal. La intensidad de ambos movimientos parece disminuir entre 1998 y 2006. Relativo a estos movimientos, el desplazamiento hacia el empleo asalariado formal y a la inactividad resulta bajo (y levemente creciente entre 1998 y 2006).

Cuentapropistas Informales: este grupo muestra una elevada intensidad de desplazamiento hacia la desocupación y el trabajo asalariado informal. Ambos flujos disminuyen significativamente luego de la crisis. El desplazamiento hacia el empleo asalariado formal de este grupo de trabajadores parece ser de muy baja intensidad. Este grupo es el de menor nivel educativo en términos promedios y el grupo de asalariados formales es el de mayor nivel educativo promedio (y posiblemente la educación sea un requisito de entrada al sector), por lo que la falta de movilidad entre ambos sectores puede estar parcialmente explicada por este hecho. De este modo, el movimiento hacia el empleo formal asalariado de estos sectores sería bajo por razones de imposibilidad y no solamente porque los individuos que eligen ser cuentapropistas valoren ciertas características del cuentapropismo que el empleo asalariado no posee, dado que, como fuera explicado, los mismos muestran alta movilidad hacia el empleo asalariado informal. 
Tabla 6

Matrices de Transición Estandarizadas: 1998-99, 2001-02, 2005-06

Población de entre 15 y 64 años

\begin{tabular}{|c|c|c|c|c|c|c|}
\hline & \multirow[b]{2}{*}{ Inactivos } & \multirow[b]{2}{*}{ Desocupados } & \multicolumn{2}{|c|}{ Formales } & \multicolumn{2}{|c|}{ Informales } \\
\hline & & & Asalariados & Cuentapropistas & Asalariados & Cuentapropistas \\
\hline Inactivos & & 75.3 & 8.5 & 13.3 & 40.9 & 36.2 \\
\hline Desocupados & 68.4 & & 44.1 & 38.0 & 136.9 & 109.8 \\
\hline Asalariados Formales & 6.5 & 42.9 & & 40.4 & 46.3 & 22.2 \\
\hline Cuentapropistas Formales & 5.8 & 63.8 & 51.5 & & 69.5 & 0.0 \\
\hline Asalariados Informales & 37.0 & 134.6 & 51.6 & 59.6 & & 101.9 \\
\hline Cuentapropistas Informales & 29.8 & 96.2 & 10.0 & 63.3 & 113.2 & \\
\hline \multicolumn{7}{|l|}{ 2001-2002 } \\
\hline & & & \multicolumn{2}{|c|}{ Formales } & \multicolumn{2}{|c|}{ Informales } \\
\hline & Inactivos & Desocupados & Asalariados & Cuentapropistas & Asalariados & Cuentapropistas \\
\hline Inactivos & & 78.1 & 6.9 & 13.5 & 54.0 & 34.0 \\
\hline Desocupados & 58.8 & & 22.6 & 72.3 & 144.5 & 128.6 \\
\hline Asalariados Formales & 8.5 & 43.1 & & 42.6 & 39.5 & 21.7 \\
\hline Cuentapropistas Formales & 10.9 & 39.1 & 29.4 & & 41.1 & 0.0 \\
\hline Asalariados Informales & 37.9 & 108.5 & 50.7 & 44.6 & & 103.6 \\
\hline Cuentapropistas Informales & 33.6 & 107.4 & 15.4 & 45.9 & 121.7 & \\
\hline \multicolumn{7}{|l|}{$2005-2006$} \\
\hline & & & \multicolumn{2}{|c|}{ Formales } & \multicolumn{2}{|c|}{ Informales } \\
\hline & Inactivos & Desocupados & Asalariados & Cuentapropistas & Asalariados & Cuentapropistas \\
\hline Inactivos & & 121.6 & 9.8 & 33.9 & 53.1 & 33.7 \\
\hline Desocupados & 87.6 & & 46.4 & 60.3 & 134.4 & 93.8 \\
\hline Asalariados Formales & 8.5 & 32.7 & & 39.7 & 33.9 & 14.0 \\
\hline Cuentapropistas Formales & 16.9 & 69.7 & 50.8 & & 56.5 & 0.0 \\
\hline Asalariados Informales & 44.7 & 87.7 & 56.3 & 28.7 & & 91.0 \\
\hline Cuentapropistas Informales & 36.0 & 55.7 & 15.3 & 79.3 & 93.0 & \\
\hline
\end{tabular}

Fuente: Elaboración propia en base a la EPH.

Aún cuando son muy informativas, las matrices de transición estandarizadas sólo tienen en cuenta que las posibilidades de moverse hacia un sector determinado dependen del tamaño relativo de dicho sector, pero no consideran que las tasas de creación de empleo pueden ser diferentes. La importancia de este hecho es mayor cuando, en una economía en movimiento, algunos sectores se expanden rápidamente, otros sólo lentamente y algunos incluso se contraen y el tipo de trabajos (la composición de empleo asalariado/cuentapropista y formal/informal) que comprende cada sector es diferente. Para tener en cuenta este aspecto se sigue la metodología empleada en Duryea, Márquez, Pagés y Scarpetta (2006), computándose matriz de transición (matrices $\boldsymbol{T}_{\boldsymbol{i j}}$ ) que incorporan el cambio en el tamaño poblacional en cada estado del mercado laboral. Estas matrices evalúan la tendencia particular a desplazarse al sector $\boldsymbol{j}$ de los trabajadores que salen del sector $\boldsymbol{i}$.

Los elementos de la matriz $\boldsymbol{T}_{i j}$ pueden expresarse como:

$$
T_{i j}=\frac{\frac{N_{i j}}{N_{i}-N_{i i}}}{\sum_{k \neq i}\left(N_{k}-N_{j j}\right)}
$$

Donde $\boldsymbol{N}_{\boldsymbol{i} j}$ es el número de individuos que se desplazan del sector $\boldsymbol{i}$ al sector $\boldsymbol{j}, \boldsymbol{N}_{\boldsymbol{i}}$ es el número de individuos en el sector $\boldsymbol{i}$ en el período inicial, $\boldsymbol{N}_{i i}$ es el número de individuos en el 
sector $\boldsymbol{i}$ en el período inicial que no hacen ninguna transición, con lo cual $\left(\boldsymbol{N}_{\boldsymbol{i}}-\boldsymbol{N}_{i i}\right)$ es el número de individuos que dejan el sector $\boldsymbol{i}$ para buscar trabajo en otro sector ("empleos destruidos)). A su vez, $\boldsymbol{N}_{\boldsymbol{j}}$ es el número de individuos en el sector $\boldsymbol{j}$ en el período final, $\boldsymbol{N}_{\boldsymbol{j} j}$ es el número de individuos en el sector $\boldsymbol{j}$ en el período final que no hicieron transición, con lo cual $\left(\boldsymbol{N}_{\boldsymbol{j}}-\boldsymbol{N}_{\boldsymbol{j} j}\right)$ es el número de individuos que legaron al sector $\boldsymbol{j}$ ("empleos creados"). Finalmente,

$$
\frac{N_{j}-N_{j j}}{\sum_{k \neq i}\left(N_{k}-N_{k k}\right)}
$$

es el ratio entre el número de trabajos creados por el sector $\boldsymbol{j}$ y el número total de trabajos creados por todos los sectores y a los que pueden acceder quienes salen del sector $\boldsymbol{i}$. Un valor de $\boldsymbol{T}_{i j}$ mayor que 1 indica una tendencia positiva de transición desde el sector $\mathbf{i}$ al sector $\boldsymbol{j}$.

La Tabla 7 muestra las matrices $\boldsymbol{T}_{i j}$ para los períodos bajo análisis.

Los resultados encontrados apoyan algunos de los hallazgos anteriores: el desempleo es el principal destino de quienes entran en el mercado laboral, siendo el empleo informal (asalariado o cuentapropista) los siguientes destinos más comunes, a la vez que la tendencia a pasar de la inactividad al empleo formal resulta ser muy baja. Por su parte, la tendencia a que un desempleado abandone el mercado laboral es más fuerte que la tendencia a que ingrese a un empleo.

Entre los sectores de empleo se observa que la tendencia a pasar del trabajo a la inactividad es mayor para los informales (asalariados o cuentapropistas) que para los trabajadores asalariados formales. Sin embargo, se observa el resultado opuesto al analizar las tendencias a pasar del trabajo al desempleo, estas son mayores para los asalariados informales que para cualquiera de las dos categorías de empleo informal. Este resultado fue especialmente fuerte durante la crisis económica.

En relación a los movimientos entre sectores de empleo los resultados también resultan ser muy interesantes. La tendencia a moverse hacia el empleo asalariado informal de los trabajadores asalariados formales es mayor que la tendencia del mismo grupo a moverse hacia el empleo por cuenta propia informal. Los asalariados informales tienen una fuerte tendencia a moverse hacia el empleo asalariado formal, pero también tienen una tendencia levemente positiva a moverse hacia trabajos informales por cuenta-propia. Finalmente, los trabajadores cuentapropistas informales muestran una tendencia muy baja a moverse hacia el empleo asalariado formal, pero tienen una significativa tendencia a desplazarse al empleo informal asalariado. 
Tabla 7

Matrices de Transición $T_{i j}$ 1998-99, 2001-02, 2005-06

Población de entre 15 y 64 años

\begin{tabular}{|c|c|c|c|c|c|c|}
\hline & \multirow[b]{2}{*}{ Inactivos } & \multirow[b]{2}{*}{ Desocupados } & \multicolumn{2}{|c|}{ Formales } & \multicolumn{2}{|c|}{ Informales } \\
\hline & & & Asalariados & Cuentapropistas & Asalariados & Cuentapropistas \\
\hline Inactivos & & 1.3 & 0.6 & 0.5 & 1.0 & 1.0 \\
\hline Desocupados & 1.4 & & 0.9 & 0.4 & 0.9 & 0.8 \\
\hline Asalariados Formales & 0.6 & 0.9 & & 1.8 & 1.4 & 0.8 \\
\hline Cuentapropistas Formales & 0.3 & 0.7 & 2.5 & & 1.1 & \\
\hline Asalariados Informales & 1.0 & 0.8 & 1.3 & 0.7 & & 1.0 \\
\hline Cuentapropistas Informales & 1.1 & 0.8 & 0.4 & 1.1 & 1.4 & \\
\hline
\end{tabular}

\begin{tabular}{|c|c|c|c|c|c|c|}
\hline & \multirow[b]{2}{*}{ Inactivos } & \multirow[b]{2}{*}{ Desocupados } & \multicolumn{2}{|c|}{ Formales } & \multicolumn{2}{|c|}{ Informales } \\
\hline & & & Asalariados & Cuentapropistas & Asalariados & Cuentapropistas \\
\hline Inactivos & & 1.3 & 0.6 & 0.4 & 1.0 & 0.8 \\
\hline Desocupados & 1.3 & & 0.6 & 0.8 & 0.9 & 1.0 \\
\hline Asalariados Formales & 0.8 & 1.1 & & 2.1 & 1.1 & 0.8 \\
\hline Cuentapropistas Formales & 0.7 & 0.7 & 2.3 & & 0.8 & \\
\hline Asalariados Informales & 1.0 & 0.7 & 1.7 & 0.6 & & 1.0 \\
\hline Cuentapropistas Informales & 1.1 & 0.9 & 0.6 & 0.8 & 1.1 & \\
\hline
\end{tabular}

\begin{tabular}{|c|c|c|c|c|c|c|}
\hline & \multirow[b]{2}{*}{ Inactivos } & \multirow[b]{2}{*}{ Desocupados } & \multicolumn{2}{|c|}{ Formales } & \multicolumn{2}{|c|}{ Informales } \\
\hline & & & Asalariados & Cuentapropistas & Asalariados & Cuentapropistas \\
\hline Inactivos & & 1.7 & 0.5 & 0.8 & 1.1 & 0.8 \\
\hline Desocupados & 1.4 & & 0.8 & 0.5 & 1.0 & 0.8 \\
\hline Asalariados Formales & 0.8 & 0.8 & & 1.9 & 1.3 & 0.7 \\
\hline Cuentapropistas Formales & 0.6 & 0.7 & 1.8 & & 0.8 & \\
\hline Asalariados Informales & 1.0 & 0.6 & 1.4 & 0.3 & & 1.1 \\
\hline Cuentapropistas Informales & 1.2 & 0.5 & 0.5 & 1.4 & 1.4 & \\
\hline
\end{tabular}

Fuente: Elaboración propia en base a la EPH.

A partir de las matrices $\boldsymbol{T}_{i j}$ pueden calcularse dos indicadores adicionales. El primero de ellos viene dado por la suma $\left(\boldsymbol{T}_{i j}+\boldsymbol{T}_{j i}\right)$, el cual mide el tamaño del flujo de trabajadores entre dos categorías laborales ajustados por la apertura relativa de una categoría dada. El segundo esta definido por el ratio $\left(\boldsymbol{T}_{i j} / \boldsymbol{T}_{j i}\right)$, y mide si hay una mayor tendencia a fluir en una dirección entre $\boldsymbol{i}$ y $\boldsymbol{j}$. Valores mayores a 2 del primer indicador implica que la movilidad entre dos sectores es mayor que el promedio de movilidad entre sectores. Valores mayores a 1 para el segundo indicador señalan que es mayor la movilidad de $\boldsymbol{i}$ a $\boldsymbol{j}$ que la movilidad en sentido inverso.

La Tabla 8 exhibe los valores de los indicadores mencionados para las transiciones desde y hacia las categorías informales, para los tres períodos bajos análisis. Los resultados muestran que es alta la movilidad entre el empleo asalariado formal y el informal, siendo los flujos relativamente simétricos, con excepción del período de crisis, donde fue mayor la movilidad desde el empleo asalariado informal hacia el asalariado formal que el movimiento contrario.

Por su parte los sectores cuentapropismo informal y asalariado informal también tienen una movilidad alta entre ellos, siendo mayor el flujo relativo de trabajadores desde el 
cuentapropismo hacia el empleo asalariado informal que viceversa. A su vez, la movilidad entre el trabajo asalariado informal y el empleo por cuenta propia informal es muy baja (la más baja movilidad entre sectores de las presentadas), siendo especialmente pequeño el flujo de trabajadores informales cuentapropistas hacia el empleo asalariado formal.

Tabla 8

Indicadores de Movilidad entre Sectores 1998-99, 2001-02, 2005-06

Población de entre 15 y 64 años

\begin{tabular}{|c|c|c|c|c|c|c|}
\hline & \multicolumn{3}{|c|}{$(T i j+T j i)$} & \multicolumn{3}{|c|}{$(\mathbf{T i j} / \mathrm{Tji})$} \\
\hline & $1998-99$ & 2001-02 & 2005-06 & 1998-99 & 2001-02 & 2005-06 \\
\hline Asalariados Informales - Inactivos & 1.98 & 2.03 & 2.11 & 1.00 & 1.00 & 0.90 \\
\hline Asalariados Informales - Desocupados & 1.71 & 1.67 & 1.52 & 0.91 & 0.81 & 0.59 \\
\hline Asalariados Informales - Asalariados Formales & 2.73 & 2.77 & 2.70 & 0.95 & 1.50 & 1.01 \\
\hline Asalariados Informales - Cuentapropistas Informales & 2.33 & 2.16 & 2.42 & 0.72 & 0.88 & 0.78 \\
\hline Cuentapropistas Informales - Inactivos & 2.15 & 1.90 & 2.03 & 1.14 & 1.36 & 1.42 \\
\hline Cuentapropistas Informales - Desocupados & 1.66 & 1.94 & 1.32 & 1.02 & 0.87 & 0.67 \\
\hline Cuentapropistas Informales - Asalariados Formales & 1.13 & 1.38 & 1.20 & 0.48 & 0.81 & 0.83 \\
\hline
\end{tabular}

Fuente: Elaboración propia en base a la EPH.

\subsection{Informalidad, Búsqueda de Trabajo y Satisfacción con el Sector de Empleo}

En esta sub-sección se analiza otro aspecto de la movilidad de los trabajadores entre categorías ocupacionales, incorporando dimensiones adicionales al análisis: la satisfacción con el sector (asalariado o cuentapropismo) en que el trabajador se encuentra trabajando y la búsqueda de empleos de los individuos empleados. A partir de agregar este nuevo elemento a la discusión, se pretenda encontrar evidencia adicional sobre la movilidad laboral y su relación con el empleo informal.

\section{Análisis Descriptivo}

En esta parte del trabajo se pretende encontrar respuestas a varias preguntas relacionadas con la movilidad laboral y la informalidad ¿Qué porcentaje de los trabajadores asalariados, formales e informales, preferirían trabajar como cuentapropistas si pudieran elegir? $\mathrm{O}$ ¿Cuántos cuentapropistas informales elegirían trabajar como asalariados si tuvieran opción de hacerlo? ¿En que medida la intención de trabajar en otro sector influye en la búsqueda de empleo?

La Tabla 9 contiene información al respecto, para la población de entre 15 y 64 años del Gran Buenos Aires durante el tercer trimestre de 2005. El 36\% de los trabajadores asalariados y cuentapropistas preferiría trabajar en otro sector, como puede observarse. Dicha proporción es mayor para los trabajadores asalariados que para los cuentapropistas y, dentro 
de cada grupo, es mayor para los informales que para los formales. En particular, se observa que el $41 \%$ de los asalariados informales dicen que de poder elegir serían cuentapropistas, mientras que el 33\% de los cuentapropistas informales dicen que en caso de poder optar elegiría ser asalariados.

¿En que medida esa disconformidad incide en la búsqueda real de empleo y, a través de ella, en la movilidad laboral? Mientras que el 25\% de los trabajadores, conformes o no con su sector de empleo, dicen estar buscando otro empleo, dicho porcentaje es $28 \%$ entre los que se manifiestan disconformes con su sector de empleo, con lo cual la influencia en la búsqueda de empleo del hecho de estar disconforme con el sector de trabajo parece ser menor. Sin embargo, existen diferencias importantes si el análisis se realiza hacia el interior de los grupos: mientras que sólo el $42 \%$ del total de los trabajadores asalariados informales buscan otro empleo, en el subgrupo de asalariados informales que desearían cambiar de sector sólo el $35 \%$ busca otro empleo ${ }^{10}$. Por el contrario, dentro de los cuentapropistas informales, mientras el $30 \%$ del total busca otro empleo, el $48 \%$ de quienes expresan no sentirse cómodos con el sector se encuentra buscando otro empleo ${ }^{11}$.

\section{Tabla 9}

Conformidad con el Sector de Empleo y Búsqueda de Trabajo Población de entre 15 y 64 años - Gran Buenos Aires - III Trimestre 2005

\begin{tabular}{ccccc}
\hline \hline & & \multicolumn{3}{c}{ Buscan otro Trabajo } \\
\cline { 3 - 5 } & Desean cambiar el & & \multicolumn{2}{c}{ Desean Cambiar Sector } \\
\cline { 3 - 5 } Categoría Laboral & Sector de Empleo & Total & No & Si \\
\hline Asalariados Formales & 36.1 & 12.9 & 10.3 & 16.8 \\
Cuentapropistas Formal & 14.2 & 13.7 & 11.8 & 29.5 \\
Asalariados Informales & 40.6 & 42.1 & 46.9 & 35.1 \\
Cuentapropistas Informales & 32.9 & 29.7 & 21.1 & 48.1 \\
\hline Total & $\mathbf{3 6 . 2}$ & $\mathbf{2 4 . 8}$ & $\mathbf{2 2 . 8}$ & $\mathbf{2 8 . 0}$ \\
\hline
\end{tabular}

Fuente: Elaboración propia en base a la EPH.

¿Cuan fuerte es entonces la búsqueda de empleo entre quienes se encuentran ocupados? ¿Ha cambiado sus características este proceso en los distintos períodos? La información mostrada en la Tabla 10 busca aportar información que ayude a responder estos

\footnotetext{
${ }^{10}$ Una posible explicación del resultado es que aquellos que prefieren seguir como asalariados busquen con más intensidad empleo dado que en el sector asalariado formal se estaban creando empleos en ese momento, mientras que los que quieren ser cuentapropistas no tienen los medios necesarios para establecerse como tal y entonces no se encuentran muy activos en el mercado laboral.

${ }^{11}$ En este caso el argumento podría ser que los cuentapropistas que manifiestan que preferirían ser asalariados son aquellos con menores habilidades para manejarse en el sector, lo que implicaría que el éxito que tienen en el mismo posiblemente sea bajo y ello los fuerce a buscar otras alternativas de empleo.
} 
interrogantes. En su primer panel muestra la proporción de trabajadores en cada sector ocupacional que se encuentran buscando otro trabajo (por diversas razones). En el segundo panel presenta el porcentaje de trabajadores de cada categoría que busca otro trabajo para reemplazar su ocupación principal actual, entre aquellos que buscan trabajo.

Como se puede ver, entre 1998 y 2002 se produjo un aumento del porcentaje de trabajadores buscando otro empleo. El incremento del total de trabajadores es explicado por aumentos en todas las categorías, con la excepción de los empleados asalariados formales. El acrecentamiento es particularmente significativo entre los cuentapropistas informales y los asalariados informales, respectivamente. Luego, entre 2002 y 2006 cae el porcentaje de trabajadores que busca otro empleo, tanto en términos totales como para dentro de cada una de las categorías. ${ }^{12}$

Respecto a los niveles relativos de búsqueda de empleo, se observa que aquellos que, en promedio, más buscaron otro empleo son los asalariados informales, seguidos por los cuentapropistas informales y formales y los asalariados formales. Estos últimos parecen ser los más conformes con su situación laboral, manteniéndose estable el porcentaje de individuos en esa categoría que buscan otro empleo, incluso durante la crisis económica de 2001-02.

Del segundo panel también se obtienen conclusiones interesantes. Presenta el porcentaje de individuos, en cada categoría y entre los que manifestaron que buscaban otro trabajo, que buscan otro empleo porque desean cambiar su ocupación principal. Dichos datos están disponibles para el período 1998-2002. Como se ve, en ese período se produjo, entre el total de trabajadores, una caída en el porcentaje de individuos que desean cambiar su ocupación principal. Sin embargo, ese resultado no se mantiene para todas las categorías laborales: entre los cuentapropistas informales dicho porcentaje no cae entre 1998 y 2002. Entre 2001 y 2002, con la ocurrencia de la crisis, se reduce el porcentaje de asalariados formales e informales que buscan trabajo para reemplazar su ocupación principal, pero aumenta el porcentaje de los cuentapropistas formales e informales que realizan dicha búsqueda. Aparentemente, la ocurrencia de la crisis aumentó la aversión al riesgo de muchos trabajadores, volviendo menos atractiva la independencia laboral, que se relaciona con ingresos más variables, como los que perciben los cuentapropistas.

\footnotetext{
${ }^{12}$ Parte de la explicación puede estar dada por el cambio metodológica en la EPH, de la modalidad puntual a la continua, aunque la pregunta que se formula es la misma en ambos casos (si el trabajador busco o no otro empleo en la semana previa).
} 
Combinando ambos paneles, se encuentra que los asalariados formales no sólo son la categoría ocupacional que parecen revelar mayores niveles de satisfacción con su trabajo, dado que son los que menos buscan otro empleo en promedio, sino que además, entre los que buscan empleo, son los que en menor medida lo hacen para sustituir su empleo principal. En la mayoría de los casos de búsqueda de otro empleo, estos trabajadores lo hacen para complementar los ingresos obtenidos en su ocupación actual.

En promedio, 1 de cada 4 asalariados informales buscaba empleo en el período 19982002 para reemplazar su ocupación principal, mostrando un relativamente mayor (respecto a las otras categorías) nivel de insatisfacción de estos trabajadores con su empleo. Dicha proporción se mantuvo bastante estable en el período bajo análisis. A ellos debe agregarse un número similar de asalariados informales que buscaban otro empleo para complementar sus ingresos o por otras razones, número que creció con la crisis de 2001-02.

Por otra parte, en promedio 1 de cada 6 trabajadores cuentapropistas informales buscó cambiar su empleo en el período. Sin embargo, dicha proporción era 1 entre 7 en 1998 y 1 entre 5 en 2002, mostrando el crecimiento de la disconformidad con el empleo por cuenta propia como empleo principal con la llegada de la crisis. Adicionalmente, se produjo un aumento en la cantidad de cuentapropistas informales que buscaban otro empleo como forma de complementar sus ingresos, entre 1998 y 2002. Esto puede estar mostrando que si bien antes de la crisis los individuos en el empleo informal por cuenta propia parecían estar en dicho sector de forma relativamente "más voluntaria" que los asalariados informales, una vez llegada la crisis el porcentaje de individuos que permanecían en cada uno de dichos sectores de forma voluntaria se volvió más similar. 
Tabla 10

Porcentaje de Individuos que Buscan otro Empleo

Población de entre 15 y 64 años

\begin{tabular}{|c|c|c|c|c|c|}
\hline & \multicolumn{2}{|c|}{ Formal } & \multicolumn{2}{|c|}{ Informal } & \multirow[b]{2}{*}{ Total } \\
\hline & Asalariado & Cuentapropista & Asalariado & Cuentapropista & \\
\hline 1998 & 18.1 & 15.8 & 42.7 & 31.9 & 26.9 \\
\hline 1999 & 18.4 & 16.9 & 44.0 & 35.8 & 28.4 \\
\hline 2000 & 18.3 & 19.7 & 44.7 & 35.1 & 28.8 \\
\hline 2001 & 19.1 & 25.8 & 46.2 & 39.9 & 31.0 \\
\hline 2002 & 18.2 & 20.3 & 50.4 & 43.6 & 33.3 \\
\hline 2003 & 14.0 & 21.1 & 41.7 & 35.6 & 27.3 \\
\hline 2004 & 12.9 & 19.2 & 40.3 & 31.6 & 25.3 \\
\hline 2005 & 11.7 & 17.2 & 37.1 & 29.0 & 22.5 \\
\hline \multirow[t]{3}{*}{2006} & 10.1 & 15.1 & 33.4 & 27.7 & 19.9 \\
\hline & \multicolumn{2}{|c|}{ Formal } & \multicolumn{2}{|c|}{ Informal } & \\
\hline & Asalariado & Cuentapropista & Asalariado & Cuentapropista & Total \\
\hline 1998 & 43.4 & 31.8 & 60.0 & 44.0 & 50.8 \\
\hline 1999 & 50.4 & 30.6 & 63.2 & 46.2 & 54.7 \\
\hline 2000 & 43.4 & 22.8 & 57.5 & 43.9 & 49.9 \\
\hline 2001 & 43.1 & 22.7 & 54.3 & 39.9 & 46.6 \\
\hline 2002 & 34.5 & 26.1 & 50.6 & 44.6 & 44.7 \\
\hline
\end{tabular}

Fuente: Elaboración propia en base a la EPH.

\section{Análisis Condicional}

Una cuestión importante que surge en este punto es si, dadas las demás cosas iguales, estar ocupado en un trabajo informal implica una mayor probabilidad de buscar otro empleo y una mayor movilidad. A continuación se busca responder dicho interrogante, a través de la estimación de un modelo de los determinantes la búsqueda de trabajo para los trabajadores ocupados.

Debido a que la variable dependiente del modelo es binaria (=1 si el individuo reporta estar buscando otro empleo, $=0$ si reporta no estar buscando otro empleo), en la estimación se utiliza un modelo logit. Como regresores se incluyen las variables explicativas tradicionalmente utilizadas en trabajos similares a este: un grupo de dummies de niveles educativos (siendo primario incompleto la categoría omitida), un grupo de dummies regionales (siendo el Gran Buenos Aires la categoría omitida), una variable que captura la experiencia potencial del trabajador y el logaritmo del ingreso horario en la actividad principal. Adicionalmente, se incluye un grupo de dummies que indican la categoría laboral del trabajador (siendo asalariados formales la categoría omitida). Estas últimas serán las variables de mayor interés en nuestro caso.

La Tabla 11 presenta los resultados de las estimaciones realizadas para el grupo de hombres de entre 15 y 64 años, para todos los años entre 1998 y 2006 . El mismo modelo fue 
estimado para mujeres de las mismas edades, arribándose a resultados similares. En la Tabla figuran los coeficientes asociados a cada uno de los regresores, los estadísticos z y el número de observaciones.

Como se podía suponer, el coeficiente asociado al logaritmo del ingreso tiene signo negativo, implicando que aumentos del ingreso laboral horario, manteniendo las demás variables en valores constantes, reducen la probabilidad de que el individuo decida buscar otro empleo. Sin embargo, se observa que la importancia de este factor (reflejada en el valor absoluto del coeficiente asociado al mismo) se reduce significativamente luego de la crisis de 2001-2002.

En general, las dummies asociadas a nivel educativo no son estadísticamente significativas, con excepción de la dummy de educación superior completa para todos los años entre 1998 y 2003, la de superior incompleto en algunos de los años anteriores a 2003, y todas las dummies en 2002. Los coeficientes asociados son positivos y crecientes en el nivel educativo, indicando que los trabajadores con mayor nivel educativo tienen una mayor tendencia a buscar otro empleo que los trabajadores menos educados. Resultados similares a los mencionados se encuentran para los trabajadores más experimentados: la mayor experiencia implica un aumento en la probabilidad de buscar otro trabajo. La importancia de este factor se ve reducida en los años finales del período analizado.

Finalmente, los resultados de las variables de interés para este trabajo resultan muy informativos. Muestran que los individuos ocupados en trabajos informales tienen una mayor probabilidad de buscar otro empleo que los asalariados formales. En particular, esa diferencia de probabilidades es mayor para los trabajadores asalariados informales en todos los años entre 1998 y 2003. La diferencia entre asalariados formales e informales es de mayor magnitud en los años 1999, 2002 y 2003. Si bien la diferencia promedio de probabilidades entre asalariados formales y cuentapropistas informales es de menor magnitud que la existente entre asalariados formales e informales, la misma es significativa en todos los años.

Como ya fuera comentado con anterioridad, los resultados sugieren un hecho de interés: si bien en los primeros años los asalariados informales mostraban una mayor probabilidad de buscar otro empleo que los cuentapropistas informales, con el tiempo la brecha comenzó a cerrarse y, luego de superada la crisis, no es claro que dicha diferencia aún se mantenga, como lo muestran los coeficientes respectivos entre 2004 y 2006. En otros 
términos, el nivel de disconformidad con el empleo dentro de las dos categorías de informalidad parece ser similar en los últimos años.

El modelo fue re-estimado definiendo la variable dependiente como $=1 \mathrm{si}$ el individuo busca otro empleo para reemplazar su trabajo principal e $=0$ en los restantes casos. Este ejercicio sólo puede realizarse para el período 1998-2002, ya que en adelante no se puede conocer las razones por las que el individuo busca otro empleo. Los resultados no varían mayormente. $^{13}$

Lo comentado en el párrafo precedente coincide con la historia sugerida por la Tabla 10: los trabajadores que muestran un mayor conformismo con su situación laboral, ceteris paribus, son los asalariados formales. Esto se manifiesta en que los mismos presentan una menor probabilidad de buscar otro empleo (ya sea para sustituir el empleo principal o por otra razón) que el resto de las categorías laborales. Si se estableciera un ranking de satisfacción con la situación laboral, los cuentapropistas informales se situarían, en promedio, por encima de los asalariados informales. Sin embargo, el ordenamiento entre estos dos últimos grupos no parece muy claro en los años posteriores a la crisis de 2001-02, lo que puede estar reflejando que dicha crisis produjo un aumento en el atractivo relativo del trabajo asalariado, en la medida que el mismo provee una corriente de ingresos fijos y seguros.

\footnotetext{
${ }^{13}$ En particular, los resultados muestran que la probabilidad de buscar otro empleo es claramente mayor para los asalariados informales que para los cuentapropistas informales en los primeros años del período. Sin embargo, en el año 2002 se produce una clara y significativa disminución en dicha brecha.
} 
Tabla 11

Modelo Logit de la Decisión de Buscar otro Trabajo (1998-2006)

Hombres de entre 15 y 64 años

\begin{tabular}{|c|c|c|c|c|c|c|c|c|c|}
\hline & 1998 & 1999 & 2000 & 2001 & 2002 & 2003 & 2004 & 2005 & 2006 \\
\hline \multirow[t]{2}{*}{ Cuentapropista Formal } & -0.167 & -0.014 & -0.276 & 0.017 & -0.284 & 0.404 & $0.519^{\star}$ & 0.086 & 0.445 \\
\hline & -0.6 & -0.1 & -1.1 & -0.1 & -0.9 & -1.1 & -1.7 & -0.3 & -1.5 \\
\hline \multirow[t]{2}{*}{ Asalariado Informal } & $0.766^{\star * *}$ & $0.882^{\star * *}$ & $0.766^{* * *}$ & $0.764^{\star \star \star}$ & $0.845^{\star * *}$ & $0.840^{\star \star \star}$ & $0.740^{* * *}$ & $0.664^{\star \star *}$ & $0.709^{* * *}$ \\
\hline & -10.2 & -11.3 & -10.0 & -9.4 & -7.4 & -6.9 & -6.6 & -6.2 & -6.2 \\
\hline \multirow[t]{2}{*}{ Cuentapropista Informal } & $0.441^{* * *}$ & $0.586^{\star * *}$ & $0.471^{* * *}$ & $0.565^{\star \star \star}$ & $0.652^{\star * \star}$ & $0.688^{\star \star \star}$ & $0.871^{* * *}$ & $0.589^{\star \star *}$ & $0.767^{* * *}$ \\
\hline & -5.5 & -7.0 & -5.7 & -6.7 & -5.5 & -5.1 & -7.1 & -5.0 & -6.3 \\
\hline \multirow[t]{2}{*}{ Ln(ingreso laboral) } & $-1.004^{\star \star *}$ & $-1.123^{\star \star \star}$ & $-1.020^{\star \star *}$ & $-1.017^{\star \star \star}$ & $-1.096^{\star \star *}$ & $-0.943^{\star * *}$ & $-0.877^{\star \star *}$ & $-0.978^{\star \star *}$ & $-0.836^{* * *}$ \\
\hline & -17.9 & -19.0 & -18.1 & -17.5 & -13.3 & -11.4 & -11.7 & -14.2 & -12.7 \\
\hline \multirow{2}{*}{ Primario Completo } & -0.036 & -0.054 & -0.154 & $-0.202^{*}$ & $0.296^{*}$ & 0.139 & -0.205 & 0.006 & -0.029 \\
\hline & -0.3 & -0.5 & -1.3 & -1.7 & -1.7 & -0.7 & -1.2 & 0.0 & -0.2 \\
\hline \multirow[t]{2}{*}{ Secundario Incompleto } & 0.089 & -0.010 & 0.031 & -0.008 & $0.314^{*}$ & 0.163 & $-0.300^{*}$ & -0.072 & 0.060 \\
\hline & -0.8 & -0.1 & -0.3 & -0.1 & -1.8 & -0.9 & -1.7 & -0.4 & -0.3 \\
\hline \multirow[t]{2}{*}{ Secundario Completo } & 0.189 & $0.229^{*}$ & -0.005 & 0.108 & $0.417^{\star *}$ & 0.088 & -0.166 & 0.009 & 0.043 \\
\hline & -1.5 & -1.8 & 0.0 & -0.8 & -2.2 & -0.4 & -0.9 & -0.1 & -0.2 \\
\hline \multirow[t]{2}{*}{ Superior Incompleto } & $0.396^{\star * *}$ & $0.528^{\star \star \star}$ & 0.066 & $0.307^{*}$ & $0.473^{\star \star}$ & $0.373^{*}$ & 0.066 & -0.185 & 0.070 \\
\hline & -2.7 & -3.5 & -0.4 & -2.0 & -2.2 & -1.7 & -0.3 & -0.9 & -0.3 \\
\hline \multirow[t]{2}{*}{ Superior Completo } & $0.542^{* * *}$ & $0.597^{\star * \star}$ & $0.523^{* * *}$ & $0.667^{\star \star \star}$ & $1.188^{* * *}$ & $0.454^{*}$ & 0.039 & 0.310 & 0.276 \\
\hline & -3.1 & -3.3 & -3.0 & -3.7 & -4.8 & -1.8 & -0.2 & -1.4 & -1.2 \\
\hline \multirow[t]{2}{*}{ Experiencia } & $0.077^{\star \star *}$ & $0.090^{* * *}$ & $0.075^{\star \star *}$ & $0.056^{\star \star *}$ & $0.068^{* * *}$ & $0.083^{\star \star *}$ & $0.041^{* * *}$ & $0.038^{\star * *}$ & $0.046^{* * *}$ \\
\hline & -7.9 & -9.0 & -7.8 & -5.6 & -4.8 & -3.3 & -3.3 & -3.2 & -3.8 \\
\hline \multirow[t]{2}{*}{ Experiencia2 } & $-0.002^{* \star *}$ & $-0.002^{\star * *}$ & $-0.002^{* * *}$ & $-0.001^{\star \star *}$ & $-0.001^{* \star *}$ & $-0.001^{* * *}$ & $-0.001^{\star * *}$ & $-0.001^{\star * *}$ & $-0.001^{* * *}$ \\
\hline & -8.6 & -9.0 & -8.9 & -5.9 & -5.0 & -3.3 & -4.2 & -3.9 & -4.6 \\
\hline Observaciones & 17778 & 15936 & 14224 & 13567 & 12396 & 6770 & 7461 & 8173 & 11573 \\
\hline
\end{tabular}

Fuente: Elaboración propia en base a la EPH.

\section{Conclusiones}

El objetivo principal del trabajo fue profundizar en la dinámica del mercado laboral en nuestro país, evaluando los movimientos de trabajadores entre sectores, prestando particular atención a los flujos desde y hacia los sectores de empleo informal.

La evidencia provista a lo largo del trabajo echa luz sobre varias características y aspectos de la informalidad laboral en Argentina, haciendo este aporte desde una perspectiva no demasiado explotada tradicionalmente: la movilidad laboral.

Los principales resultados encontrados no permiten realizar afirmaciones definitivas a favor de una u otra de las teorías explicativas de la informalidad laboral (escape o exclusión). Por el contrario, los resultados sugieren que ninguna de las teorías puede, individualmente, explicar el fenómeno de la informalidad en nuestro país. Sin embargo, aunque los resultados indican cierto grado de complementariedad entre ambas teorías, pareciera que el componente de exclusión tiene una mayor presencia en Argentina, al menos en los últimos años del período bajo análisis.

Varios son los hechos que apoyan esta última afirmación: 
- Entre extremos del período se produjo un aumento de la informalidad total, tonel máximo durante la crisis de 2001-02. La evolución del empleo asalariado informal, que aumentó su participación en el empleo total y en el empleo informal total, explica gran parte de esta tendencia. De este modo, hacia 2006 la composición del empleo informal contaba con una mayor participación de asalariados, y una menor proporción de cuentapropistas, que en 1998.

- El empleo formal tiene mayores niveles de estabilidad (o menores de movilidad) que el informal. En particular, el empleo asalariado formal presenta niveles de estabilidad cercanos al 90\%. Los empleos informales son menos estables y existe un vínculo fuerte entre los mismos y la inactividad y el desempleo. Esto da alguna idea de que los individuos con ocupaciones formales valoran mucho trabajar en ese sector de actividad.

- En el período 2005-06, superada la crisis económica, se observa un incremento de la movilidad desde los sectores informales al empleo asalariado formal. Sumado a lo dicho en el párrafo anterior, este resultado parece indicar que buena parte de la fuerza laboral valora especialmente el empleo asalariado formal, en particular luego de la crisis económica. Los limitados movimientos desde otros sectores hacia el mismo tienen que ver con que dicho sector no genera un número suficiente de puestos de trabajos para absorber a todos los que quisieran trabajar allí.

- Casi la totalidad de los movimientos hacia la formalidad desde la informalidad se dan a través de la alta movilidad relativa que existe entre el empleo asalariado formal y el informal. Por el contrario, los flujos entre el empleo asalariado formal y el empleo por cuenta propia informal son significativamente bajos, en especial los movimientos desde el segundo sector hacia el primero. ¿Supone esto que los cuentapropistas informales se encuentran cómodos en su sector y prefieren no tomar empleos asalariados formales? La evidencia encontrada al respecto niega la pregunta, ya que la estabilidad en el sector cuentapropista informal es alta y, en especial las salidas desde este sector son hacia el empleo asalariado informal, lo que implica que parte de los cuentapropistas están dispuestos a aceptar empleos asalariados, sólo que, por alguna razón, no pueden conseguir dichos empleos en el sector formal. Posiblemente el menor nivel educativo de estos trabajadores sea la explicación de esa imposibilidad, ya que los requisitos educativos parecen ser una de las formas de asignar los relativamente escasos puestos de trabajos en el sector asalariado formal. 
- La evidencia que relaciona movilidad laboral, informalidad, deseo de cambiar de sector de trabajo y búsqueda efectiva de empleo también resulta muy interesante. Parece existir una clara diferencia de actitud con respecto a la búsqueda de otro empleo entre aquellos cuentapropistas que declaran que prefieren trabajar en ese sector $\mathrm{y}$ entre aquellos que dicen que preferirían ser asalariados: mientras $21 \%$ de los primeros buscan activamente otro empleo, dicho porcentaje asciende a $48 \%$ entre los segundos (información existente sólo para el Gran Buenos Aires, III Trimestre de 2005).

- Los niveles de búsqueda de empleo dependen del sector de actividad y de los años específicos del período que se estudien. Aquellos que menos buscan cambiar de empleo son los que trabajadores en el sector formal y, dentro de este grupo, los asalariados. Dentro de los trabajadores informales, los asalariados son quienes más buscan cambiar de empleo. Si bien durante la crisis se incrementó el porcentaje de individuos disconformes con su empleo, este porcentaje se redujo nuevamente a partir de la recuperación económica. Asimismo, el ranking entre sectores se mantuvo a lo largo del período.

- La evidencia anterior es reforzada por los resultados del modelo logit de probabilidad de buscar otro empleo. Controlando por las características usuales observables, encontramos que los asalariados informales tienen, en promedio, una mayor probabilidad de buscar otro empleo que los cuentapropistas informales, quienes a su vez tienen mayor probabilidad que los asalariados formales. Sin embargo, las probabilidades de buscar otro empleo para las categorías informales son prácticamente iguales o incluso mayores para los cuentapropistas, luego de la crisis. Ello podría indicar que la crisis aumentó la deseabilidad del empleo asalariado, en la medida que el mismo implica un ingreso más cierto que la actividad por cuenta propia.

En resumen, la mayoría de los resultados obtenidos son de sumo interés en la discusión de la informalidad en nuestro país. Si bien la evidencia no es concluyente al respecto y se requiere profundizar la investigación, tanto en términos teóricos como empíricos, la misma parece clara en varios sentidos.

El empleo asalariado formal parece ser la categoría laboral más deseada por la mayoría de los trabajadores argentinos, aumentando incluso esa deseabilidad luego de la crisis. La posibilidad de acceso a beneficios sociales y a un empleo más estable, en el 
contexto de un país con muchos vaivenes y escasas redes de contención para quienes no se encuentran en el mercado laboral, parecen potenciar las ventajas relativas de este tipo de empleo.

El sector informal no es un grupo homogéneo. Claramente los trabajadores asalariados informales se encuentran en dichos empleos por "exclusión”, no sólo tienen menores ingresos laborales, sino que también sus empleos son menos estables y no les permiten el acceso a los diferentes beneficios sociales vinculados al empleo: seguro de salud, vacaciones pagas, aportes jubilatorios, etc.

Respecto a los cuentapropistas informales la evidencia es mixta. Si bien se puede afirmar que buena parte de ellos se emplean en este sector voluntariamente (escape), dado que sus preferencias por ciertas características de estos empleos (mayor independencia y flexibilidad en términos generales), la evidencia parece indicar que una porción importante de estos trabajadores permanecen en el sector porque no consiguen ingresar a empleos informales.

La crisis de 2001-02 es un hito importante en varios sentidos, no sólo porque se alcanzaron los menores niveles de formalidad laboral, sino porque parece haber influido en las preferencias de los participantes en el mercado laboral respecto al sector preferido de empleo: mientras en 1998 la idea de informalidad voluntaria (escape) tenía una mayor fuerza explicatorio de la informalidad, dada la mayor participación en le total de informales de los cuentapropistas informales y de su menor tendencia a buscar otros empleos, el advenimiento de la crisis provocó un crecimiento de los asalariados informales dentro del empleo informal, situación que se mantuvo aún después de superada la crisis y, como fue visto en la última parte del trabajo, también se fue modificando la probabilidad relativa de buscar otro empleo entre asalariados y cuentapropistas informales, siendo dicha probabilidad prácticamente igual en los últimos años. De este modo, la teoría de exclusión como explicación de la informalidad en nuestro país gana fuerza, ya que crece la importancia de la parte del sector informal claramente excluido (los asalariados informales) al mismo tiempo que la parte del cuentapropismo informal que no parece ser voluntaria también parece crecer, tal como lo manifiesta el aumento de la probabilidad relativa de buscar otros empleos que se observa en este grupo. 


\section{Bibliografía}

Duryea, S., Marquez G., Pagés, C. y Scarpetta, C. (2006). For Better of For Worse? Jobs and Earnings Mobility in Nine Developing and Emerging Economies. Mimeo.

Fields, G. (1990). Labor market modelling and the urban informal sector: theory and evidence. In OECD, The informal sector revisited. Paris

Gasparini, L. y Tornarolli, L. (2006). Labor Informality in Latin America and the Caribbean: Patterns and Trends from Household Survey Microdata. Background Paper para el Flagship Report del Banco Mundial “Informality in Latin America and the Caribbean”, 2006.

Guha-Khasnobis, B., Kanbur, R., y Ostrom, E. (2006). Beyond formality and informality. Introduction to Linking the formal and informal economy: concepts and policies, forthcoming, EGDI-WIDER, forthcoming.

Henley, A., Arabsheibani, G.R., y Carneiro, F. (2006). On defining and measuring the informal sector. World Bank Policy Research Working Paper 3866.

Maloney, W. (1999). Does informality imply segmentation in urban labor markets? Evidence from sectoral transitions in Mexico. World Bank Economic Review 13.

Perry, G., Maloney, W., Arias, O., Fajnzylber, P., Mason, A., y Saavedra, J. (2007). Informalidad: Escape y Exclusión. Banco Mundial.

Pradhan, M. y van Soest, A. (1995). Formal and informal sector employment in urban areas of Bolivia. Labor Economics 2.

Portes, R. y Schauffler, R. (1993). Competing perspective on the Latin American informal sector. Population and Development Review 19 (1).

Saavedra, J. y Chong, A. (1999). Structural reform, institutions and earnings: evidence from the formal and informal sectors in urban Peru. Journal of Development Studies 35 (4). 